\title{
Tizian
}

\section{Die heilige Hure}

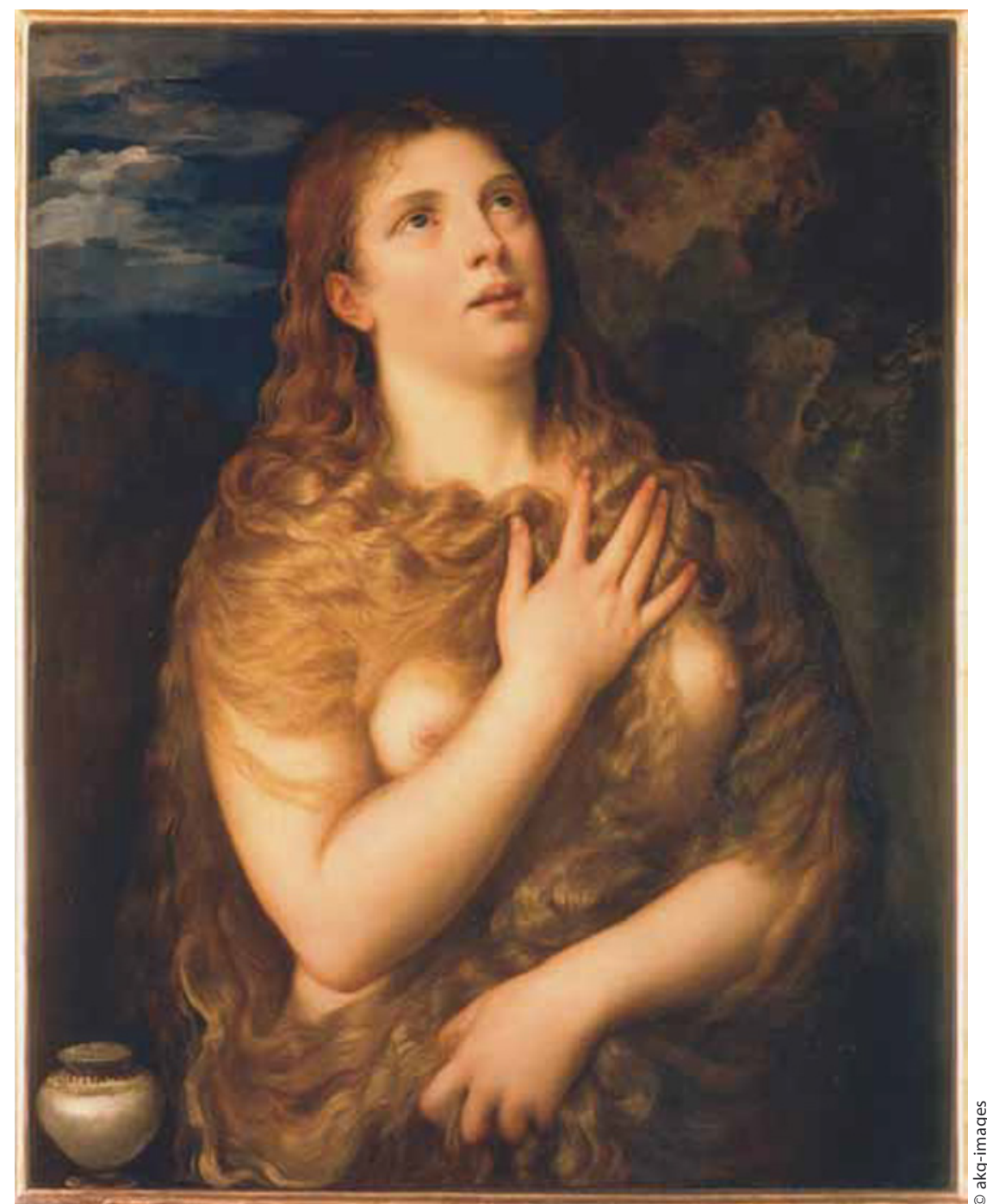

„Büßende Maria Magdalena“, um 1533, Tizian, eigentlich Tiziano Vecellio (ca. 1490-1576)

\author{
War sie tatsächlich eine Hure \\ bevor sie eine Heilige wurde? Ist \\ sie eine verfemte Apostelin? \\ Die Hüterin des heiligen Grals? Die \\ heimliche Geliebte Jesu? Gar die \\ Mutter seiner Kinder? In den \\ letzten Jahren hat die Figur der \\ Maria Magdalena die Phantasie \\ vieler Zeitgenossen wieder einmal \\ nachhaltig bewegt. Stoff für \\ (Männer-)Phantasien liefert sie \\ jedoch bereits seit vielen Jahrhun- \\ derten - und das vor allem den \\ Malern. Ihr wohl spektakulärstes \\ Porträt stammt vom führenden \\ Vertreter der venezianischen \\ Malerei Tizian.
}

$\mathrm{M}$ aria Magdalena wird in allen vier biblischen Testamenten erwähnt. Unter den Frauen, die Jesus folgten, nimmt sie offensichtlich eine Sonderstellung ein. In allen Evangelien ist sie auch bei der Kreuzigung anwesend. Nach der Auferstehung Christi ist sie es, der er als Erste erscheint und die Botschaft an seine Jünger aufträgt.

Außerhalb der Evangelien ist die Maria Magdalena, die dann in die Kirchengeschichte eingeht, jedoch eine Kunstfigur, in der mehrere Legenden verschmelzen. Zu dieser Legende gehört auch, dass die angebliche ehemalige Prostituierte den Rest ihres Lebens zur Buße in die Wüste zieht, wo sie sich 47 Jahre lang von drei Broten ernährt. Ihre Kleider zerfallen, aber ihr Haar wächst so lang, dass sie damit ihren nackten Körper vollständig bedecken kann.

In der Malerei verkörpert Maria Magdalena den Typus der klassischen "Sünderheiligen“ - und liefert damit ein willkommenes Gegenbild zur keuschen Gottesmutter Maria, deren stereotype Darstellung wenig Raum für Sinnlichkeit bot. In das Bildnis der reuigen Sünderin konnte man dagegen alles hineinpacken, was sonst in der christlichen Kunst nicht unbedingt gestattet war: Luxus und Lüsternheit, sinnliche Verlockung und verführerische Nacktheit.

Tizians Bild ist dafür ein Paradebeispiel. Der Großmeister der venezianischen Renaissance malt seine Maria Magdalena nicht unbedingt so, als habe sie sich die letzten vier Jahrzehnte nur von drei Broten ernährt. Ihre Körperhaltung und ihr Gesichtsausdruck können als Zeichen reuiger Buße interpretiert werden überaus sinnlich wirkt das Ganze immer noch. Nicht zuletzt demonstriert Tizian natürlich auch, warum er als der größte Kolorist der italienischen Malerei gilt. Die langen Haare drapiert er um den Körper der Büßerin wie ein glitzerndes Negligé. Was eigentlich ihre Blöße verbergen soll, wird eher zu einem leuchtenden Rahmen, der ihre nackten Brüste noch besonders betont.

Ob dies im 16. Jahrhundert wirklich ein religiöses Erbauungsbild war, mag man mit einigem Recht bezweifeln. Eine derartige Zurschaustellung verlockender Nacktheit diente wohl eher dem Stimulieren voyeuristischer Begierden als der Stillung frommer Bedürfnisse. Aber was ist Malerei anderes als die Kunst, unsere Augenlust zu befriedigen? Und wer wusste das besser als Tizian. 